\title{
The clinical features of the Cohen syndrome: further
} case reports

\author{
CLAIRE NORTH*, M A PATTON*, M BARAITSER*, AND R M WINTER† \\ From ${ }^{*}$ the Department of Clinical Genetics, Institute of Child Health, 30 Guilford Street, London WC1N \\ 1 EH; and †Clinical Research Centre, Northwick Park. Hospital, Watford Road, Harrow, Middlesex.
}

SUMmaRY We report the clinical features of six patients with the Cohen syndrome. The characteristic features include mental retardation, truncal obesity, prominent incisors, and tapering digits. Pelviureteric obstruction and epilepsy are reported as possible new features of this syndrome.

In 1973 Cohen et al described three cases of a syndrome, the major features of which include obesity of mid-childhood onset, microcephaly, hypotonia, mental retardation, a characteristic craniofacial appearance, and slender tapering fingers and toes. Since then 28 cases have been reported. ${ }^{2-11}$ Autosomal recessive inheritance is well established.

A recent publication by Norio et al ${ }^{11}$ reviewed published reports and suggested that a chorioretinal dystrophy was a new and important feature of the syndrome. We report a further six cases including two sib pairs to give a clearer clinical picture of this syndrome. We confirm the importance of the ophthalmic abnormalities including chorioretinal dystrophy.

\section{Case reports}

The patients range in age from 13 months to 16 years. There are four boys and two girls including two sib pairs (cases $3 / 4$ and 5/6) (fig 1). All the patients described were born to non-consanguineous British parents. The clinical features of the six patients are summarised in the table and the facial features are illustrated in fig 2.

There are a number of previously unreported features. The first patient had a right hydronephrosis secondary to pelviureteric obstruction. He required reimplantation of the ureter. At 12 years of age he had a number of epileptic seizures. The fifth patient presented with a right ureteric calculus at 4 years of age. The calculus was removed and biochemical analysis showed it to contain calcium,

Received for publication 6 March 1984. Accepted for publication 11 July 1984.
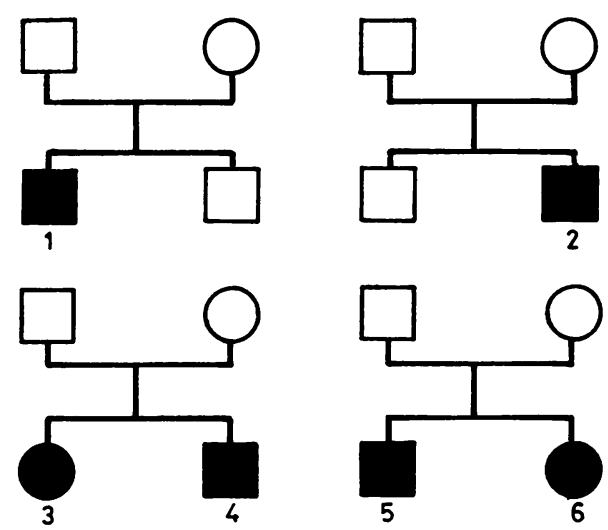

FIG 1 Family pedigrees of the six reported patients.

ammonium, phosphate, and urate. Calcium, oxalate, urate, and cystine excretion were normal. Subsequent investigation demonstrated bilateral pelviureteric obstruction which required pyeloplasty. This patient also had epileptic seizures and a mildly abnormal glucose tolerance test.

\section{Discussion}

Our patients show many of the characteristic features described by Cohen et al. ${ }^{1}$ All six are hypotonic, truncally obese, mentally retarded, and share similarities of facial appearance, including high nasal bridge, open mouth, and large prominent incisors.

Low birth weight was not a striking feature, although postnatal growth retardation was a feature in all our cases. The obesity was characteristically 
TABLE Clinical features of the Cohen syndrome.

\begin{tabular}{|c|c|c|c|c|c|c|c|c|}
\hline \multirow[t]{2}{*}{ Clinical feature } & \multicolumn{6}{|l|}{ Case } & \multirow[t]{2}{*}{ Other } & \multirow[t]{2}{*}{$\%$} \\
\hline & 1 & 2 & 3 & 4 & 5 & 6 & & \\
\hline Sex & $\mathrm{M}$ & $\mathrm{M}$ & $\mathrm{F}$ & $\mathrm{M}$ & M & $\mathrm{F}$ & & \\
\hline Low birth weight & + & - & - & - & - & - & $19 / 31$ & 54 \\
\hline Short stature & + & + & + & + & + & + & $19 / 31$ & 68 \\
\hline Truncal obesity & + & + & + & + & + & + & $27 / 31$ & 73 \\
\hline Microcephaly & - & - & - & - & - & - & $19 / 31$ & 52 \\
\hline Hypotonia & + & + & + & + & + & + & $28 / 31$ & 92 \\
\hline Epileptic seizures & + & - & - & - & + & - & $(1 / 31$ & 6 \\
\hline Delayed puberty & + & + & NA & NA & NA & NA & $13 / 17$ & $(79)$ \\
\hline Prominent nasal bridge & + & + & + & - & + & + & $29 / 31$ & 92 \\
\hline Open mouth & + & + & + & + & + & + & $26 / 31$ & 87 \\
\hline Prominent incisors & + & + & + & + & + & + & $20 / 31$ & 70 \\
\hline Short philtrum & - & - & + & + & + & - & $28 / 31$ & 84 \\
\hline Maxillary hypoplasia & - & - & + & - & - & - & $25 / 31$ & 70 \\
\hline Antimongoloid eye slant & - & + & + & + & + & - & $16 / 31$ & 54 \\
\hline Small ears & - & - & - & - & - & - & $6 / 31$ & 16 \\
\hline Tapering fingers and toes & + & + & - & + & + & + & $28 / 31$ & 89 \\
\hline 2-3 syndactyly & - & - & - & - & - & - & $11 / 31$ & 30 \\
\hline Hyperextensible joints & + & + & - & - & - & - & $18 / 31$ & 54 \\
\hline Cubitus valgus & + & - & - & - & - & - & $18 / 31$ & 52 \\
\hline Genu valgum & - & - & - & - & - & - & $16 / 31$ & 43 \\
\hline Strabismus & + & - & + & + & + & + & $14 / 31$ & 52 \\
\hline Myopia & + & - & - & - & - & - & $16 / 31$ & 46 \\
\hline Coloboma & + & - & + & + & - & - & $2 / 31$ & 14 \\
\hline Chorioretinopathy & + & - & + & + & - & - & $12 / 31$ & 41 \\
\hline Abnormal ERG & ND & ND & + & + & ND & ND & $6 / 12$ & $(57)$ \\
\hline Leucopenia & - & - & - & - & - & - & $6 / 31$ & 16 \\
\hline Pelviureteric obstruction & + & - & - & - & + & - & $0 / 31$ & 5 \\
\hline
\end{tabular}

$\mathrm{NA}=$ not applicable. $\mathrm{ND}=$ not done.
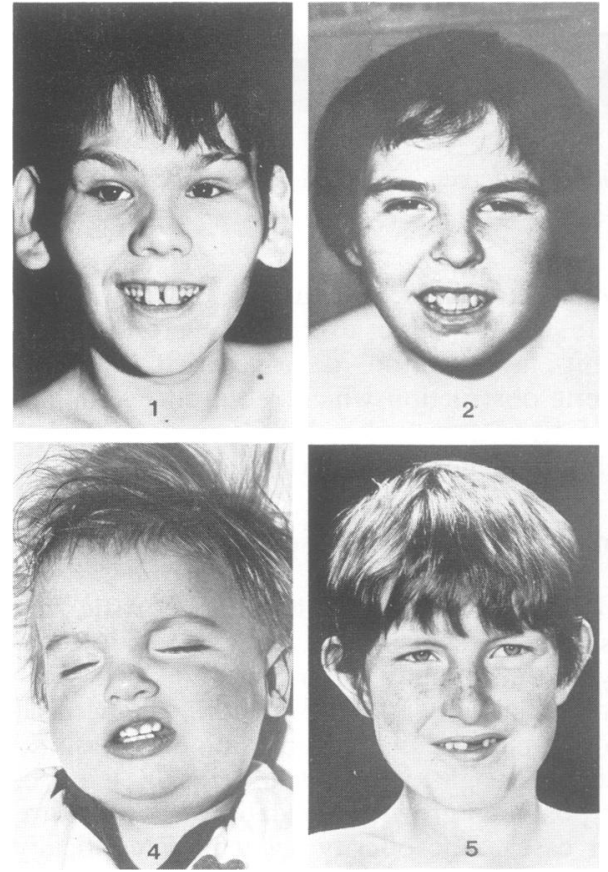

5
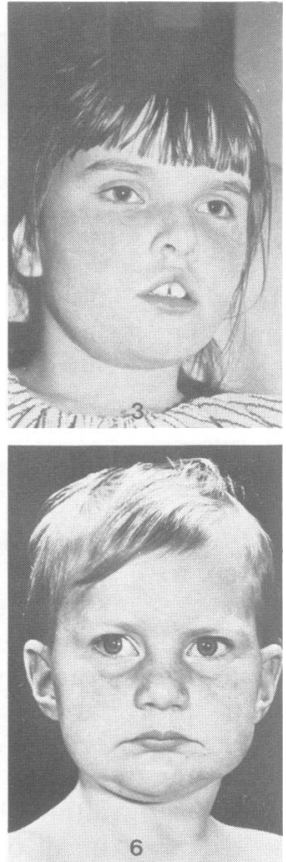

FIG 2 Facial features of the six reported patients with the Cohen syndrome. (Cases $N$ labelled as in the table.) 


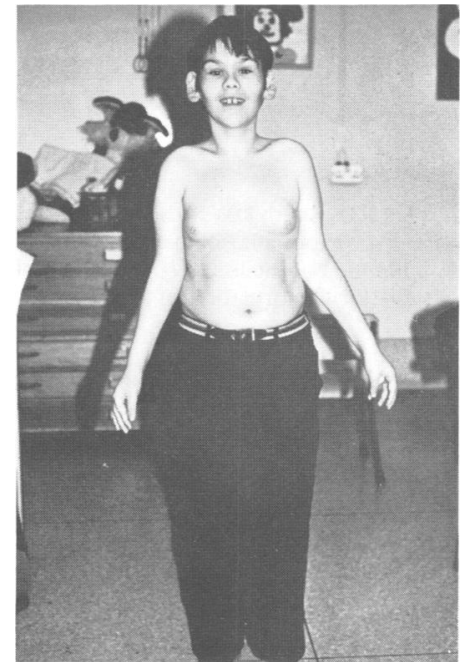

FIG 3 The distribution of truncal obesity (case 1).

truncal rather than generalised and is well illustrated in fig 3. One of our patients (case 2) had a generalised obesity but came from a family with a history of obesity.

Hypotonia was a feature in all our patients, although we did note that the severity was variable even between sibs.

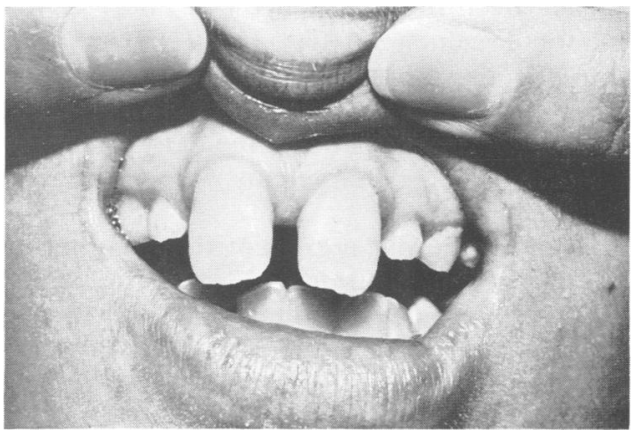

FIG 4 The prominent incisors seen in case 1. The incisors appear large in the presence of a normal philtrum.

Delayed puberty was striking in our two older patients (cases 1 and 2 ). In both, the testes and penis were small and there were no secondary sexual characteristics. Chromosomes were normal. The other four patients were prepubertal, but in one (case 5) there was a rudimentary scrotum and small testes and penis.

The facial features we found most helpful in recognising the syndrome were the prominent incisors with the open mouth appearance combined with the short philtrum. Norio et al ${ }^{11}$ suggested that the incisors appear more prominent because of the reduction in the philtrum length. Our first case

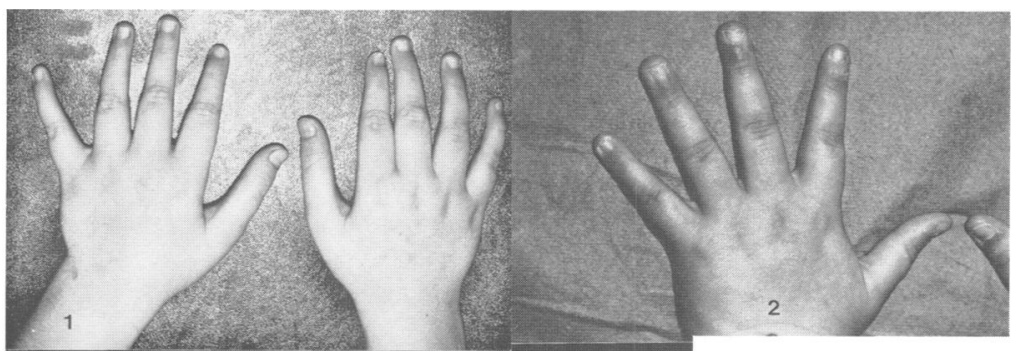

FIG 5 The tapering appearance of the fingers in the Cohen syndrome (cases 1,2, and 5).
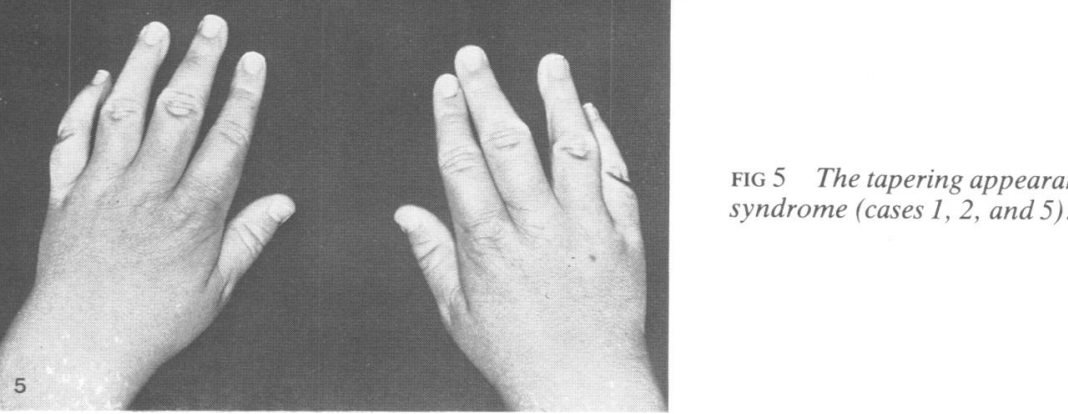
shows that even in the absence of a short philtrum the incisors are enlarged (figs 2 and 4). The primary dentition is delayed but otherwise normal.

Unlike Norio et al $^{11}$ we did not find the lobulus of the ears small. In our patients the ears tended to be large and protruding. Large ears were also reported by Kousseff. ${ }^{4}$

Tapering of the distal ends of the fingers (fig 5) and toes has been reported in 33 out of 37 reported cases. The cause of this finding is unclear. In two of our cases (5 and 6) we noted that it was associated with limitation of flexion of the distal interphalangeal joints.

Five of our six patients had ophthalmic abnormalities, the most common of which was strabismus. Three patients had chorioretinopathy and both of the two tested had abnormal electroretinograms. In the first case there was a bilateral colobomata of the lower eyelids with a mottled retina and normal optic discs. In the third case there was retinal dysplasia, bilateral choroidal and disc colobomata, and abnormal optic discs. In the fourth patient there were pigmentary changes in the macula, colobomata of the optic discs, and an orbital cyst adjacent to the right optic nerve was seen on the CT scan.

The pelviureteric obstruction in cases 1 and 5 has not been reported previously and it is possible that this is an additional feature of the syndrome. In the presence of urinary infection or loin pain radiological examination of the urinary tract should be undertaken in this condition.

We thank Dr J Wilson for permission to publish cases 5 and 6 . We are also grateful to $\operatorname{Dr} M \mathbf{M}$
Cohen for reviewing the diagnosis in cases 5 and 6. Dr M Patton is supported by a grant from the Child Health Research Appeal Trust.

\section{References}

1 Cohen MM, Hall RD, Smith DW, Graham CB, Lampert KJ. A new syndrome with hypotonia, obesity, mental deficiency and facial, oral and limb abnormalities. J Pediatr 1973;83:280-4.

2 Carey JC, Hall BD. Confirmation of the Cohen syndrome. $J$ Pediatr 1978;93:239-44.

${ }^{3}$ Balestrazzi P, Corrini L, Villovi G, Bolla MP, Casa F, Bernasconi S. The Cohen syndrome: clinical and endocrinological studies of two new cases. J Med Genet 1980;17:430-2.

4 Kousseff BG. Cohen syndrome: further delineation and inheritance. Am J Med Genet 1981;9:25-30.

5 Ferre P, Fournet JP, Couspotin C. Le syndrome de Cohen, une affection autosomique recessive. Arch Fr Pediatr 1982:39:159-60.

- De Toni T, Cafiero V. Sexual development in a girl with Cohen syndrome. J Pediatr 1982;100:1001.

7 Sack J, Friedman E. Cardiac involvement in the Cohen syndrome-a case report. Clin Genet 1980;17:317.

${ }^{8}$ Fryns JP, Van Der Berghe H. The Cohen syndrome. J Genet Hum 1981;29:449-53.

${ }^{y}$ Coecke T, Majewski F, Kauther MD, Sterzel U. Mental retardation, hypotonia, obesity, ocular, facial, dental and limb anomalies (Cohen syndrome). Eur J Pediatr 1982;138:338-40.

10 Friedman E, Sack J. The Cohen syndrome: report of five new cases and a review of the literature. J Cran Genet Dev Biol 1982;2:193-200.

11 Norio R, Raitta C, Lindald E. Further delination of the Cohen syndrome; a report on chorioretinal dystrophy, leukopenia and consanguinity. Clin Genet 1984;25:1-14.

Correspondence and requests for reprints to $\mathrm{Dr}$ M A Patton, Department of Clinical Genetics, Institute of Child Health, 30 Guilford Street, London WC1N 1EH. 